\title{
The Support and Practice of the "Grand Sports View" to the Cultivation of Applied Talents in Independent Colleges-Take South China Institute of Software Engineering as an Example
}

\author{
Gaoxuan Wang \\ South China Institute of Software Engineering, Guangzhou, Guangdong, 510990, China
}

Keywords: Independent college, Grand sports view, Applied talent, Cultivation.

\begin{abstract}
This paper analyzed the concept support of the "grand sports view" in the cultivation of applied talents in South China Institute of Software Engineering by using the methods of literature review and field investigation. Through the implementation of the "One Body and Two Wings" education management, a practical demonstration was made for the cultivation of applied talents in physical education curriculum reform, sports spirit cultivation, the shaping of sports culture, the integration of sports industry and sports public service into colleges and universities. It had proved that the independent colleges should broaden the educational function of sports in the cultivation of applied talents, integrate the diversified educational function of sports into the talent training system of independent colleges, and achieve win-win in the construction of physical subject and the cultivation of applied talents.
\end{abstract}

\section{Introduction}

South China Institute of Software Engineering.GU (hereinafter referred to as "SISE.GU"), founded in 2002, is the only one software institute among more than 300 independent colleges in China that features IT talents cultivation. It focuses on the combination of regional economy and social development in talent cultivation, and cultivates IT applied talents based on the application of information technology in all walks of life. In recent years, the school leadership has taken a broad and long view to explore the concept and practice of cultivating applied talents in the view of grand sports, opening up a new way of college physical education.

\section{Raise of problem}

At present, the economic structure of our country is in the accelerative transformation period. A large number of high quality applied talents are needed by all walks of life to cope with the industrial upgrading. The development of applied undergraduate education and the cultivation of high-quality applied talents needed by the society have become the orientation and training objectives of independent colleges. The grand sports view gets rid of the narrow view of sports which is just to master sports skills and improve physical health quality, stands at a higher level to position the role of sports in the cultivation system of applied talents, integrates the function of physical education into the talent cultivation system of the school to become an important part in the talent cultivation process to serve the development of current social. The grand sports view is a sports system with scientific contents and various structures and functions.

\section{The connotation and characteristics of applied talents in independent colleges}

Compared with academic talents, applied talents refer to those talents who possess certain professional knowledge and skills, can translate academic research results into social productivity or apply social productivity into social production practice, and directly create social material and wealth. ${ }^{[2]}$ The main characteristic of applied talents are to take scientific principles and the nature as 
research objects, engage in work closely related to specific social production, labor and life, can create direct economic benefits and material wealth for the society. ${ }^{[3]}$ The talent cultivation goal of independent colleges in our country is basically high quality applied talents oriented by the social needs and employment market. The students are required not only to have solid professional knowledge and skills, but also comprehensive professional skills such as good physical quality, psychological quality, innovative ability and social adaptability. As a basic subject in university talent cultivation system, college physical education can play an important role in cultivating students' comprehensive professional ability.

\section{The concept support of grand sports view for the cultivation of applied talents in independent colleges}

\subsection{The healthy support of sports for the cultivation of applied talents}

There was a famous saying by Chairman Mao, "the body is the capital of the revolution", pointing out that one must have a number of abilities to make a career, but all of these must have a precondition -- good health. Only when you are healthy, can you be full of passion and vitality in work and study, improve work or study efficiency and cope with various challenges in work. ${ }^{[4]}$ In the cultivation of applied talents, independent colleges should take "health first" as the guiding ideology, so that college students can master the skills and habits of sports and make healthy reserve for future work.

\subsection{The psychological effects of physical exercise on the cultivation of applied talents}

In 2002, the ministry of education issued the "Outline of teaching guidelines for physical curriculum of national higher education", which pointed out the basic teaching goals in five areas: sports participation, sports skills, physical health, mental health and social adaptability. Among them, mental health and social adaptability are particularly important for the cultivation of applied talents in modern society. Under the increasingly fierce social competitive pressure, the psychological quality of enterprise employees must have good anti-pressure ability. At the end of 2017, a 42-year-old employee of ZTE, Ou, who was widely concerned by the news media, jumped to his death after leading a conversation by the leader, because of the pressure of working crisis, supporting parents and children and repaying the mortgage. ${ }^{[5]}$ Although this was an accidental event, it was also a mirror in the process of social transformation and development. The psychology of enterprise employees was under pressure from society, work, family and other aspects. Therefore, as an independent college that mainly cultivates social applied talents, it should strengthen the cultivation of psychological anti-stress and anti-frustration ability of college students, so as to enhance their adaptability to the society.

\subsection{The cultivation of practical ability of college students by sports practice}

Physical education, as a highly practical subject, comes from practice and acts on practice. The characteristic of this subject and the cultivation of applied talents come down in one continuous line. It is through the participation of practice-theory-practice activity that college students can constantly improve their practical ability and better adapt to the demands of future work. It has been proved by practice that sports has an unique advantage in cultivating people's practical ability, on the one hand, sports has always been an important part of education in schools and has a profound educational foundation; on the other hand, sports has formed a complete set of theory and practice system in the aspects of cultivating people's operational ability, cerebral ability, strain ability, innovation ability and team spirit ${ }^{[7]}$. The professional quality given by applied talents is completely consistent with the spirit of sports education.

\subsection{The participation of sports in promoting the improvement of college students' social adaptability}

The value of cultivating applied talents comes down to be reflected in the level of meeting the 
needs of social development, undertaking social responsibility, good interpersonal communication and mastering social survival skills that can be achieved. Sports practice provides a good platform for college students to cultivate their comprehensive social practice ability, and a broad space for college students to improve their social adaptability. College students can cultivate their interpersonal skills by organizing sports activities, and cultivate their working abilities by participating in sports activities as volunteers and judges, and they can also cultivate their teamwork ability, tenacious fighting spirit and the strong psychological quality of daring to challenge opponents by participating in competitions.

\subsection{The cultivation of sports spirit to college students' team spirit and innovation ability}

Currently, the adjustment of social and economic structure is mainly the transformation and upgrading of enterprises, which is transformed from labor intensive to the information, intelligentization and other high-tech fields, and from the energy consumption type to the ecological friendly type. Sports participation can play a very good role in cultivating college students. Through sports practice, college students constantly break through themselves, innovate themselves, discover potential, and cultivate the confidence and courage of innovation, and through the activities of the team project, they can cultivate the ability of team collaboration and division of labor. It is sports spirit that shapes college students' individual excellent qualities of "transcending oneself and melting team".

\section{The practice of "grand sports view" in the cultivation of applied talents in South China Institute of Software Engineering.GU}

\subsection{The guiding ideology of cultivation of applied talents of "grand sports view"}

The applied talent cultivation model of SISE.GU takes employment as the target and market demands as the orientation. In the cultivation of applied talents, the institute pays attention to the combination of multiple disciplines, and highlights the cultivation of high-quality applied talents with "thick foundation, broad caliber, good innovation and strong ability", as well as the all-round development of morality, intelligence, sports and aesthetics. In the process of cultivating applied talents, the school attaches great importance to the role of sports education, and has implemented the talent cultivation mode of "one body, two wings, multi-point support and layer by layer promotion". The structure is shown in Figure 1.

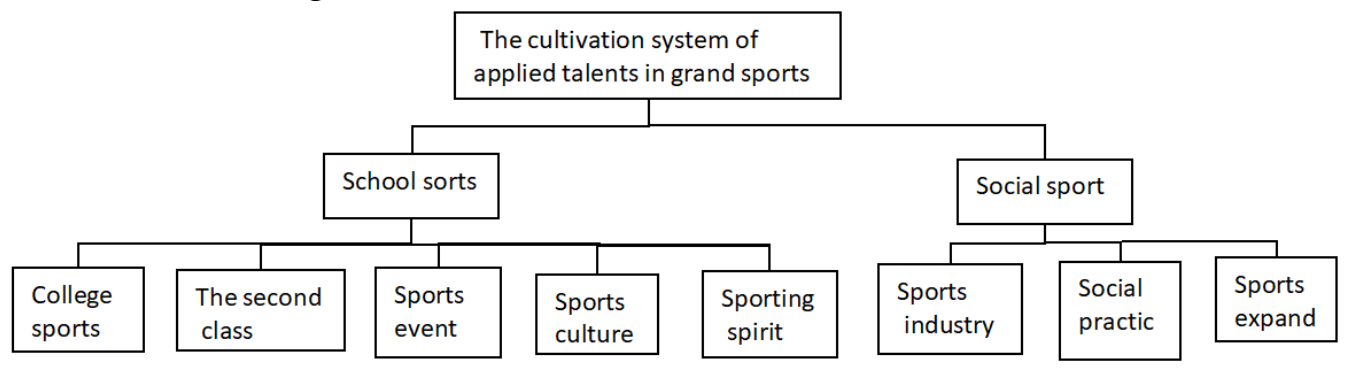

Figure 1. The structure chart of talent cultivation system of grand sports view

\subsection{The reform of college physical education course contributes to the cultivation of applied talents}

College physical education course is one of the basic courses for talent cultivation in colleges and universities in China. Like other independent colleges, SISE.GU plays a multidisciplinary linkage effect in the cultivation of applied talents, realizing the perfect combination of general knowledge education and professional education. In the reform of curriculum structure system of college physical education, SISE.GU first considers the cultivation of applied talents suitable for the discipline development and social needs. Sports socialization function education is add into theory learning, and modular teaching is implemented in practical course, which is divided into three 
modules: the compulsory course module, the elective course module and the practical and innovative course module. Compulsory courses start from the first semester of the first year of college, mainly to exercise the physical qualities of college students. Learning contents include basic physical quality items such as speed, endurance and flexibility. Starting from the sophomore year, the optional course module mainly focuses on the improvement and expansion of college students' interests and specialties. Each student is required to choose at least two different specialty programs. The junior and senior years are the practical innovation modules, which mainly encourage college students to actively participate in social sports practical activities outside the school. These measures have clearly indicated the direction for the sports reform of independent colleges, and improved the enthusiasm of students' sports practice and teachers' guidance outside the school.

In order to make up for the lack of class hours of the first class, SISE.GU has increased the teaching management of the second class of physical education. It makes full use of software which is its advantage subject to jointly develop the information teaching tool such as fitness running software APP by the software department and the sports department led by the dean's office and physical education online course to monitor students' extracurricular activities. In the past year, the second class of physical education in SISE.GU was in full swing, not inferior to the first class, playing a very good fitness effect.

\subsection{The integration of sports culture and the education concept of applied talents in colleges}

SISE.GU is located on the beautiful riverside of Liuxi river. The design of one-river and two-lakes garden makes the campus be the picturesque landscape. The flowers bloom in four seasons, especially in the season of kapok blossoming every year, the campus is full of tourists. The beautiful natural environment provides a good external environment for the sports culture construction of the college. The college attaches great importance to the positive role of sports culture in the cultivation of applied talents. Regular fitness month and sports meeting are held every semester to provide a platform for students to participate in sports and communicate with each other. In particular, the "SISE Running Family", which was founded by the president of the school, has become an outstanding card of the school. The "SISE Running Family" is a long-distance running team established by the labor union of the school in July 2013. Up to now, it has developed into a large team, with unified team logo and clothing, perfect organization and advanced training equipment base. In December, 2016, the staff marathon running activity base of Guangdong province was settled in SISE.GU. Nowadays, in the focus of the college leaders, the sports culture has permeated into every aspect of the school's cultural construction, which has a complete organizational guarantee of system construction, structural system and propaganda planning.

\subsection{The cultivation of sports spirit to the quality of applied talents}

Sports spirit is a vivid reflection of human excellent character and lofty ideal. It is mainly composed of four major elements: humanistic spirit, heroism spirit, fair competition spirit and team spirit. Its core is transcendence ${ }^{[8]}$. SISE.GU integrates sports spirit into its talent cultivation system, adding the practice of moral evaluation of socialist core values into college PE course, cultivates students' ideological and moral qualities of patriotic, dedication, integrity and friendship. By holding a series of sports events, SISE.GU has become the inspiring tradition of cultivating the sports spirit of college students. Through the cultivation of sports spirit, generations of people of SISE.GU have become high quality applied talents with patriotic and dedication, fearless of difficulties, innovation, solidarity and collaboration.

\subsection{The support provided by sports industry for the social practice of applied talents}

The sports industry is still an emerging industry in China, with a rapid rise. The document of the State council predicted that the sports industry would have at least 5 trillion yuan of market space in the next decade. With the rapid development of the Internet, big data and artificial intelligence, SISE.GU makes full use of its school-running speciality, guides the students to deeply integrate with the sports industry in terms of professional development and self-employment to develop smart 
sports. On the one hand, the college has set up a start-up base to encourage incubation teams with innovative ideas and good market planning to enter. For example, the "public sports ecosystem based on social sports and monopoly" created by the "Initial C" Team and the multi-functional running software of "sports, health, social contact, shopping and public benefit" created by the "Constant Team" Team. The second aspect is to cooperate with enterprises to educate people, with the well-known enterprises such as Zezhong software, China intelligence technology, Haiyi software and Tongsu technology.SISE.GU takes smart sports as platform to cultivate the applied talents and serves the national fitness by the market operation of the sports industry. It provides students with good social practice opportunities and improves their social practice ability to find a good breakthrough for the cultivation of social applied talents. Meanwhile, it has brought considerable economic benefits to the college. It attracts millions of investment every year and brings good social benefits for the school in image publicity and concept confidence of talent cultivation.

\section{Summary}

The grand sports view is a multilevel, open and interdisciplinary large system, rather than an isolated system of pure significance of physiological exercise. The core of the the grand sports view is to educate people, and the most basic function is to enhance physical and mental health of people. The foundation of independent colleges is the cultivation of applied talents. In terms of the education management of grand sports view, we can draw on the experience of education model of SISE.GU, give full play to the diversified functions of sports education, and improve the future social adaptability of college students.

\section{Acknowledgement}

This research was financially supported by the Provincial key platforms and major scientific research projects of colleges and universities in Guangdong (Grant NO. 2017GXJK256); Education research project of South China Institute of Software Engineering. GU (Grant NO. ky201730).

\section{References}

[1] Yifei Xie, Guiyin Gao. The formation and establishment of contemporary grand sports view, Journal of Shandong Sport University, 2014, 10(21):10-13.

[2] Hong Zhou, Richeng Deng. Research on the evaluation of applied talents in China [EB/OL]., "http://www.china.com.cn/".china.com.cn/news/zhuanti/09rcbg/2009-09/21/content_18568744.htm.

[3] Weijian Liu, Chaunjin Wang. The connotation of applied talents from the division of talent types, Journal of changzhou institute of technology, 2006, 6(24):98-100.

[4] Health management. For six reasons exercise can greatly improve the efficiency of work and study [EB/OL]. http://www.jianshu.com/p/a9edf5284303,2015.09.15.

[5] Southern Metropolis Daily. The 42-year-old employee fell dead from company building!, 2017,12-15.

[6] Jingbo Zhang. Research on the relationship between physical exercise and stress, interpersonal relationship and mental health, Kunming: Yunnan normal university, 2014. 5:48.

[7] Zhining Lian. The ultimate concern of sports to people from the perspective of Marxist philosophy, Journal of Nanjing Sport Institute, 2013, 12(8):131.

[8] Li Huang. The cultural connotation and value construction of sports spirit, Sports science, 2007, 27(6):88 -96. 